\title{
Patterns of Conceptual Change in Evolution
}

\author{
Sherry S. Demastes \\ Department of Educational Studies, University of Utah, Salt Lake City, Utah 84112
}

Ronald G. Good

Department of Curriculum and Instruction, Louisiana State University, Baton Rouge, Louisiana 70803

Patsye Peebles

University Laboratory School, Louisiana State University, Baton Rouge, Louisiana 70803

\begin{abstract}
The purpose of this study was to investigate the patterns of students' conceptual restructuring within the theoretical framework of biologic evolution. The study draws on conceptual change theory in an effort to define the limits of the theory and suggest other models of restructuring. Through a series of 17 structured and open-ended interviews with each of 4 participants, the students' changing conceptions about facets of evolutionary theory were documented throughout the school year. Interview questions were developed from the wealth of alternative conceptions documented in the literature, and many interview techniques were employed to assure the mode validity of all research findings. The conceptual change documented demonstrates that many conceptions in this content area are closely interwoven, so that a change in one conception requires a change in many others. Four patterns of conceptual change were seen: (a) cascade, (b) wholesale, (c) incremental, and (d) dual constructions. Of these 4 , only 2 conform to the changes described by conceptual change theory. The other two patterns suggest that different models of conceptual restructuring are required for further science education research.

Many science educators have begun to recognize that the process of conceptual restructuring "lies at the heart of science teaching and learning" (Wandersee, Mintzes, \& Novak, 1994, p. 201). These authors suggest that science educators should begin to examine closely the actual process of conceptual change. For the past decade, the theory of Posner, Strike, Hewson, and Gertzog (1982), referred to as the Conceptual Change Model (CCM), has represented one of the most illuminating models for the process of conceptual structuring with its emphasis on the kinds of evidence needed for rationally directed conceptual change. Within the original CCM and its subsequent expansions (Hewson, 1981, 1982), a learner's major organizing conceptions are understood to undergo a process of holistic conceptual change as a new conception is judged to be more intelligible, plausible, and fruitful than its competing predecessor.
\end{abstract}


Strike and Posner (1992) further explicated the intended scope of the conceptual change theory. They stressed that this normative theory is designed to identify the kinds of evidence needed for the restructuring of a major (paradigmatic) concept. Because of its epistemologic grounding, the conceptual change theory is not intended to be an empirical description of learning. Strike and Posner explained that while the CCM is meant to describe how paradigmatic concepts might be altered, they do not foresee any immediate classroom applications. However, the CCM does have definite implications for how learning may occur, and the latter aspect has received a great deal of attention as science educators attempt to apply this theory in the classroom (Bishop \& Anderson, 1990; Hewson, 1981; Hewson \& Thorley, 1989; Smith, 1991).

Although Strike and Posner (1992) explained that they did not envision the CCM as "a detailed account of learning" (p. 150), a review of related science education literature provides a "thick description" of learning as it is described by application of the CCM. Aspects of this description include the types of knowledge that are understood to change, the pathway of knowledge restructuring, prerequisites for conceptual change, driving mechanisms for change, and the requirement of acceptance of the new conception.

Some authors understand the CCM in broad terms as a model of learning (Hewson \& Hewson, 1992). However, others are more specific in their application and use the CCM to describe only the change of major, organizing conceptions (Posner et al., 1982). As explained by Strike and Posner (1992), the CCM is not meant to describe all learning. Instead, it is meant to model changes in fundamental conceptions that serve to organize other learning events.

Often, learning is understood to involve two patterns of restructuring (Hewson, 1981; Hewson \& Hewson, 1992; Posner et al., 1982). The first, conceptual capture or assimilation, is the process through which a new conception is added to or reconciled with what the learner already knows, analogous to Carey's (1985) weak restructuring. A second type of learning, conceptual exchange or accommodation, is the process through which one conception replaces the use of another, analogous to Carey's strong restructuring. CCM's original theorists intended the theory to describe only the process of conceptual exchange (Hewson, 1981; Posner et al., 1982), while subsequent applications of the model have included both forms of restructuring (Hewson \& Hewson, 1992). Even if one applies the more narrow application of the CCM, the pattern of conceptual exchange requires further definition. There is a tension in descriptions of conceptual exchange between notions of gradual and wholesale change. Conceptual exchange is described as both a process of holistic exchange, distinctly "not an evolutionary process" (Schwedes \& Schmidt, 1992, p. 199), and a gradual process absent of sudden changes, so that competing conceptions remain but eventually only one is consistently applied by the learner (Hewson \& Hewson, 1992; Strike \& Posner, 1985).

There is more agreement between theorists on the prerequisites for conceptual change, and it is this aspect of the model that has received the majority of attention. As was seen in the original formulation, learners must experience dissatisfaction with their original conception as well as judge a competing conception to be more intelligible, plausible, and fruitful than the alternative in order for the new conception to be used in place of the old (Chinn \& Brewer, 1993; Hewson \& Hennessey, 1992; Hewson \& Hewson, 1992; Hewson \& Thorley, 1989; Posner et al., 1982).

The requirements for conceptual change as described by the CCM make the process appear to be largely rationally driven and logically based (Strike \& Posner, 1985). While these characteristics are in tune with the original formulation, the rationality implicit in the theory has been the focus of subsequent revisions. Strike and Posner (1992) described the original theory as overly rational and suggested that a learner's motivation and value of the subject material play important roles in a conceptual ecology. A conceptual ecology is understood to be the concep- 
tual context for learning, a context that includes aspects of the learner's prior knowledge, analogies, metaphors, and metaphysical and epistemologic commitments. Each component of a conceptual ecology is understood to play important roles in guiding the process of conceptual change. Extending this thought, Strike and Posner suggested that a conceptual ecology is interactionist in nature so that conceptions are both acted on by the ecology and act to change this ecology. The description of an interactionist conceptual ecology goes far in changing the linear nature of change as it was originally described. Pintrich, Marx, and Boyle (1993) built on this tension as they explained that a learner's belief about her or his role in the classroom and about herself or himself as a learner are major components of the conceptual ecology and thus play a large role in altering the nature of change that can occur. However, the rational, logical basis of the CCM remains, but as a process that is acted upon by extrarational motivations.

The final aspect in the description of change as outlined in the CCM is the matter of the learner's acceptance of the new conception. In the original formulation of the CCM, conceptual exchange must be characterized by acceptance or "belief" in the new conception (Hewson, 1981; Posner et al., 1982; Strike \& Posner, 1985). This view is in concert with the overall description of conceptual exchange that describes true learning as rationally based and requires the learner to accept the plausibility of the conception and consistently apply the conception in new situations. This description is problematized by Smith (1991), who explained that "conceptual change does not necessarily involve conviction or affect," (p. 62) although he acknowledged the importance for students to apply the new concept and recognize its fruitfulness.

Clearly, the CCM model has been very useful in building our understanding of what it means to learn science. The model provides a rich description of learning; however, as demonstrated by the preceding discussion, this model is not without discordance in its applications. Two of the original CCM theorists, Strike and Posner (1992), have admitted that the CCM was not meant to be the complete theory of learning and have called for studies which show the boundaries and blind spots of the CCM. In a similar vein, Millar (1989) called for studies that emphasize the pathways that individuals follow as they come to understand scientific concepts. Our research was designed to investigate the limits and conditions of applicability of the conceptual change theory within a specific content area and to suggest possible refinements or alternatives to this theory. We accomplished these goals by analyzing the conceptual restructurings of individual learners during the learning process to identify and understand patterns of change. This research is part of a larger study in which several aspects of conceptual change (including the influence of conceptual ecologies, patterns of change, and influence of instruction) were documented (Demastes, 1994).

Although there are many detailed descriptions of conceptual change in physics (Brown, 1995; Hewson \& Hewson, 1992; Schwedes \& Schmidt, 1992), far less has been accomplished within the discipline of biology. Biological evolution was selected as the content area of study within biology because of the history of alternative conceptions research accomplished within this theoretical framework (Bishop \& Anderson, 1990; Brumby, 1984; Cummins, Demastes, \& Hafner, 1994; Demastes, Trowbridge, \& Cummins, 1992; Jimenéz, 1992) and its fundamental importance in the discipline of biology. The theory of evolution provides a means of tying together the many disciplines found in biology to form a single, coherent, and fluid science. Thus, the conceptual framework of evolution contains several paradigmatic conceptions which influence and are influenced by the learner's overall conception of biology. (For a discussion of these conceptions, see Bishop and Anderson, 1985, and Rutherford and Ahlgren, 1990). It was hoped that this area would prove fruitful for describing the change of major, organizing conceptions. 


\section{Methods}

The research questions should guide the choice of the methods used in their investigation. The goals of our research included describing the patterns of conceptual restructuring our learners experienced and achieving an understanding of how students come to understand evolution. These goals required that an ideographic approach be used. Such an approach involved the exploration of students' conceptual frameworks on their own terms and not in terms of their congruence with some predetermined standard (Driver \& Easley, 1978). Clearly, some form of interpretive research, focusing on complexity and context, was required.

\section{The Course}

A high school Biology II class was observed daily throughout the 1992-1993 school year. This class was selected based on its teacher (Patsye Peebles) and her teaching methods. Our selection of the research site was deliberate, based on the uniqueness of the instruction and the students and curriculum of the class. Previous research had demonstrated that the students in Peebles' classes were very capable of applying the theory of evolution to understand ambiguous biologic data (Cummins, Good, Demastes, \& Peebles, in press) and she used evolution as the unifying theme of her biology classes.

The selection of this school as a site for the study had drawbacks. The school is a university laboratory school with a very homogeneous, economically privileged student population. (The majority of the students are white, middle-class students.) The students attending this school cannot be considered representative of the population of the public school in our area because of the requirement for both tuition and transportation. Thus, one could argue that we investigated conceptual change in a very economically privileged, narrow segment of the population. However, previous research indicates that conceptual change seldom occurs during instruction on evolution (Bishop \& Anderson, 1990; Brumby, 1984; Deadman \& Kelly, 1978: Jensen \& Finley, 1994). This class was selected because it provided the best opportunity to document conceptual change toward a scientific understanding of evolution.

\section{Course Goals}

The class studied was a Biology II course in which evolution was both taught as a distinct unit and integrated throughout the course. This is not an advanced placement course, but is considered by the teacher to be a capstone class which integrates knowledge from many of the sciences as suggested by the National Research Council (1990). The teacher's goal for the students in this class was to:

. . . teach them how to look at things and think about them. I [stress] thinking skills in the context of biology. Hopefully, at the end of [this course] they will be interested enough in biology to want to continue learning about the content of biology. And, ah, they will know how to do that on their own if necessary. So that, whatever comes up that involves a biological issue, they will be literate enough to understand, appreciate, make commitments or choices. (p. 19)

\section{Curriculum and Teaching Methods}

Nine units were addressed in this Biology II course; the nature of science, dinosaurs, animal behavior, animal rights, genetic techniques, anatomy, evolution, microbiology, and 
anthropology. While evolution was addressed in a 10-day formal unit, this topic was a focal point of instruction throughout the course. The teacher's method of instruction on this topic is of particular interest. Unlike many traditional biology courses which emphasize the mechanism of evolutionary change, this teacher emphasized the knowledge about evolutionary theory. Topics emphasized in the course include: (a) historical development of the theory, (b) evidence for evolution, (c) evolutionary relationships, (d) patterns of evolution, and (e) aspects of evolutionary explanations. The formal unit on evolution occurred after the majority of the midyear interviews.

Students were expected to discuss implications of evolutionary theory in whole-group discussions, small-group work, journal entries, and written reports. This socially based approach answers Settlage's (1992) call for application of instructional conversations in the instruction of evolution.

\section{The Participants}

Interview participants were selected from the 22 students in the class for the larger study, the results of 3 of which will be reported here. Their selection was based on a purposeful sampling designed to provide the widest diversity in the students' content knowledge, orientation toward science, and acceptance of evolutionary theory (Patton, 1989). The selection was informed by their responses to pretest questions concerning the process of evolution (Bishop \& Anderson, 1985), the teacher's judgment, the 1 st month of classroom observations, and initial open-ended interview sessions.

Each of the 3 interview participants differed markedly in terms of their conceptual frameworks, epistemological commitments, scientific and religious orientation, and acceptance of evolution theory. However, two characteristics that each participant shared were an acceptance of the importance of academic knowledge and a willingness to participate in the research. (Pseudonyms are used for all research participants.)

Stephanie was an articulate, literate, thoughtful senior girl who excelled in all of her academic work (with the exception of mathematics). With an appreciation for many disciplines such as literature, philosophy, science, world religions, and particularly anthropology, she continually changed the context through which she understood natural phenomena. However, Stephanie rejected the relativist label for herself because she referred to the natural world for confirmation of her conceptions. Stephanie's interest in religion was a major feature of her conceptual ecology. Thus, she experienced a great deal of conflict in trying to negotiate the intersection of her religious beliefs and her scientific knowledge for the origin and development of life. Stephanie's strong religious and anthropologic interests were the lenses she most frequently used to understand evolutionary issues.

Meredith was a quiet senior girl who struggled to achieve high grades in her academic work. Meredith placed value only on topics that she understood as having practical importance in her education. She valued knowledge for education's sake but understood much of her classroom knowledge to have little personal importance. Although Meredith was religious, she had achieved a successful negotiation of the science-religion conflict through the consistent use of a strict dichotomy of the application of scientific and religious knowledge.

Tyler was a talkative, energetic senior girl who excelled in biology but struggled with many of her other classes. She was religiously inclined and because of this experienced much anxiety when her personal beliefs and scientific understandings conflicted. During conflicts, she consistently turned toward an authority for a resolution. This pattern is seen in all areas of Tyler's academic work as her religious belief conflicted with her newly constructed scientific knowledge. The effects of the pattern were magnified by her epistemological understanding of science 
as a body of static, proven knowledge. Perhaps the most unsure of all the participants, Tyler was interested in biology but did not use a mechanistic understanding of the natural world. Instead, she understood the natural world in terms of aesthetics and did not look for an underlying function or mechanism for biological phenomena.

The first author was a participant-observer in the classroom, school, and homes of these students. This role is a fluid continuum, so that the researcher's involvement was as varied as teaching a lesson on concept mapping, working with students as a member of a small group, or sitting quietly in the back of the classroom taking field notes (Bogdan \& Biklen, 1992). Students in the Biology II class, the course teacher, parents of the interview participants, school principal, and guidance counselor were also interviewed.

\section{Data Sources}

The sources of data used in this study include: (a) daily classroom observations, (b) interviews arranged throughout the school year, (c) written pre- and posttest exams, and (d) classroom artifacts (including participants' class examinations, journal entries, and homework assignments).

Interviews were the dominant means of data collection. The first author conducted a set of 17 interviews with each of the 3 interview participants. The interviews ranged from very structured, such as participants' explanations for their exam responses, to very open ended, with our discussions of religious beliefs and personal implications of acceptance of evolutionary theory. For the open-ended interviews, the initial questions were very broad, and later questions narrowed as we attempted to describe and verify the participants' conceptions. The research areas explored with the open-ended interviews ranged from areas such as students' (a) personal characteristics, (b) attitudes toward religion, (c) ideas of schooling, (d) conceptions of mutations, species, and patterns of evolution, and (e) attitudes toward pseudosciences. Open-ended interviews were also conducted with the teacher on a regular basis to inform our description of the class and participants.

The structured interviews focused on the participant's explanation or production of a graphic. To determine if the conceptions were used in a meaningful way by the participant, the interviews were designed to require the students to apply their knowledge in description, prediction, and explanation activities (Smith, Blakeslee, \& Anderson, 1993). Many ideas for the structure of these interviews were taken from White and Gunstone (1992). The topics of the interviews were informed by previous studies of students' alternative conceptions in this area (Bishop \& Anderson, 1990; Clough \& Wood-Robinson, 1985; Kargbo, Hobbs, \& Erickson, 1980). The interview topics included: (a) explanations of the mechanisms of evolutionary change in response to the Bishop and Anderson (1985) pre- and posttest exam, (b) concept mapping sessions focusing on the nature and mechanism of evolutionary change, (c) interviews about instances of biological diversity and possible patterns of evolutionary change, (d) prediction interviews involving knowledge of genetics and mutation events, (e) a sorting task requiring an explanation of an evolutionary event in a hypothetical population, and (f) a word sort requiring students to select terms to describe their understanding of biological evolution.

The study was designed so that many of the structured interview subjects overlapped. In this manner, the mode validity of the descriptions of the conceptual frameworks was ensured; that is, the descriptions generated were a reflection of many modes of investigation (White \& Gunstone, 1992). (See the Appendix for a sample of the graphics and questions used in the structured interviews.) 


\section{Data Collection Techniques}

The techniques employed to collect the data used in the study include: (a) transcriptions, (b) field notes, and (c) field journals. The transcripts from audio- and videotaped interviews form the main body of data for our research. Also, any class period in which evolution was addressed was transcribed. For the open-ended interviews which did not require graphics for interpretation, the interviews were audiotaped. For the structured interviews, the participants were both audiotaped and videotaped. While the audiotapes were used for the bulk of the transcriptions, the videotapes provided additional information detailing the students' movements and expressions as they reacted to the material.

\section{Analysis}

Analytical comments paralleled the data from field notes, field journals, and all transcriptions. Data analysis was accomplished by defining or isolating theories and concepts directly from the data as described by Glaser and Strauss (1967). Each area mentioned by the students about the theoretical framework for evolution was summarized. In an effort to systematize the descriptions of the participants' conceptual frameworks, the categories of conceptions that surfaced during the study were placed on a template. Each participant's transcripts were reviewed and their frameworks were described on a template. This summary process was completed at three intervals for each participant during the research process. Through comparison of the templates, instances of conceptual change were identified.

The data from each student were analyzed separately and then the individual students were compared in a componential analysis. The componential analysis allowed the initial steps from a contextual understanding of each participant toward a generalization of insight constructed from the study. The analysis was shared among the three researchers. Because this was a reflexive study, another essential part of the analysis involved participant verification of our emerging theories. As themes were identified, they were discussed with the students and their ideas were used to reshape our original analysis.

\section{Results}

\section{Patterns of Conceptual Change}

Through an analysis of each participant's conceptual frameworks, four patterns of conceptual change were identified. These include: (a) cascade of changes, (b) wholesale changes, (c) incremental changes, and (d) dual constructions.

\section{Cascade of Changes}

Often the change of one conception allowed a sequence of conceptual changes to occur. An example of this is demonstrated in Stephanie's and Meredith's use of need as the origin of variation. While this conception remained in place, other associated conceptions also remained in an alternative state. But a change in the controlling conception allowed for a cascade of associated changes. The sequence of this cascade and examples of the data from Meredith's interviews which suggest this sequence include the following. 
Need Was Replaced by Mutation as the Origin of Variation.

Initial Framework.

[These are Meredith's verbal responses to a pretest question about the evolution of webbed feet in a population of ducks.]

M: Well, ah, webbed feet allows, I mean, ah, better, for better swimming. Ah, it was something that ah, it was an evolved trait, wasn't it?

Researcher (R): Uh-huh [Yes]

M: And it's not a chance mutation. It was something that was necessary.

R: Okay, so ah, so how do things evolve?

M: Well, ah, it's mainly as far as when they need to, ah, adapt to certain conditions. (A 19, initial framework)

\section{Midyear Framework.}

[The following are Meredith's responses to a card sort in which a population of rabbits changes from predominantly white in color to predominantly brown.]

R: How did those rabbits get there? These brown ones?

M: There was a mutation. (A 233, midyear)

[The following are Meredith's responses as she constructed a concept map.]

R: Do you see mutation as an important part of evolution? [It was located in the upper levels of her map.]

M: Yeah.

R: Why?

M: Because it's the whole thing that, that ah, I mean you couldn't have evolution if you didn't have a mutation that produced the variation. (A299, midyear)

The Conception of Patterns of Evolution as Tied to the Environment Was Replaced by a Conception of Evolutionary Patterns Having a Random Component.

Initial Framework.

[The following are Meredith's written responses to a pretest question about the evolution of blindness in cave salamanders.]

M: Cave salamanders, living in a dark environment, did not need to see. Over the years they evolved to lose this unnecessary function. (Pretest 8 , initial)

\section{Midyear Framework.}

[The following are Meredith's responses to a card sort in which a population of rabbits changes from predominantly white in color to predominantly brown.]

R: Do you know what caused those mutations?

M: It's just, ah, I think, by chance that happens. (A 230, midyear) 
[The following are Meredith's responses about a word sort.]

M: Yeah, keep random [in the group of evolutionary terms]. Because you have, ah, I guess it refers, referring to the, ah, mutations or whatever or the, the changes that occur, that, you know, cause evolution.

R: Okay.

M: And it's not something ordered. It's not planned to be that way. . . Chance? Ah, I'd probably just, I'd probably leave that [in the group of evolutionary terms], because it's, ah, you know, it's by chance that these ah, mutations occur. (A 244, midyear)

The Conception of an Inextricable Action of Natural Selection and Production of Variation was Replaced with a Conception of the Separate Actions of These Two Processes.

Initial Framework.

[The following are Meredith's responses to her pretest question about the evolution of speed in a population of cheetahs.]

M: Ah, I said that, ah, they needed to run faster [pause]. It was necessary for them to catch their prey to survive. Ah, it occurred because of the need for the adaptation. . . I I mean, it was necess-they needed to run faster to catch food so it happened. (A 25, initial)

Year-End Framework.

[The following are Meredith's responses as she constructed a concept map.]

M: [Reading her map] Evolution occurs through mutation of a species and then I went the other way from mutation. I said, ah, mutation is either beneficial, either beneficial or nonbeneficial. And, ah, beneficial mutations will produce more successful species by natural selection. ...

R: [Reading Meredith's map] Yeah, okay. Natural selection acts on nonbeneficial mutation and then ... ?

M: That trait doesn't reproduce. (A 298-299, year-end)

The Conception of the Unit of Evolutionary Change as Being the Entire Population Was Replaced by a Percentage of the Entire Population.

Initial Framework.

[The following are Meredith's verbal responses to a pretest question about the evolution of webbed feet in a population of ducks.]

R: So, when you say "population of ducks" change, what does that mean?

M: Like, they're, ah, that's all the ducks that live somewhere, like by a lake or something.

R: So will all the ducks have this change?

M: Yeah, in evolution I guess they're all gonna change. (A 22, initial) 


\section{Year-End Framework.}

[The following are Meredith's verbal responses to a posttest question about the evolution of webbed feet in a population of ducks.]

M: If, ah, the ducks were forced to live in where there wasn't water . . . ah, I, I think a lot of ducks would die because they weren't suited for their environment. . . . But it's possible that, ah, you know, another mutation would occur that would produce nonwebbed feet in a few of them. (A 312, year-end)

It is difficult to determine the exact sequence of each of these conceptual changes, because the cascade always occurred over a short time span. However, previous work indicates need as the controlling conception of this cascade (Demastes \& Good, 1993). Reiner (1992) explained that some conceptions are more robust than others and are used by students to understand a wide variety of phenomena. diSessa (1993) characterized physics conceptions that are more far reaching in their effects on students' learning as phenomenological primitives. In terms of the cascade of conceptual changes, need may be such a conception. In the terminology of Posner et al. (1982), need plays an important role in the learner's conceptual ecology for evolution, controlling and organizing the learning that can occur.

Aside from identification of the controlling conception, documentation of this series of changes is insightful. Millar (1989) suggested that a model of knowledge fragments instead of conceptual frameworks may be a more fruitful model for students' understandings. The data depicting the cascade of changes conflict with this model of knowledge fragments and indicate that some knowledge exists in an interconnected conceptual framework as described by Duit (1991). Interconnected changes as described in the cascade are understandable given the description of some alternative conceptions as paradigmatic conceptions offered by Strike and Posner (1992). If the paradigmatic conception shifts and the framework is to be kept in equilibrium, other conceptions must shift in response.

\section{Wholesale Conceptual Change}

Using the theory of conceptual change as described by Posner et al. (1982), restructuring of major organizing conceptions is understood to be wholesale, so that the prior conception is completely discarded in favor of the new conception based on the relative merits of the evidence supporting the competing conceptions. Stephanie underwent the most striking example of conceptual change as it is commonly described in the literature. At the outset of the course, she understood science to use the Lamarckian conception for the origin of variation within a population.

\section{Initial Framework.}

[The following are Stephanie's responses to pretest questions about the evolution of blindness in a population of cave salamanders.]

ST: I said that because the salamanders live in complete darkness, light is not a necessity. After many generations of salamanders that became blind, the offspring were eventually born without sight. . . . Ah, actually, maybe that's not right. Maybe the ones that originally went into the cave became blind and their offspring were born without sight and they became blind and maybe the process just happened quicker because they could function without sight. . . . So maybe because they don't use it, they lose it. (D 23, initial) 
However, this use/disuse explanation was tentatively suggested, and within $5 \mathrm{~min}$, she voiced her discomfort.

[The following are Stephanie's responses to her answers to the pretest question on the evolution of blindness in a population of cave salamanders.]

ST: I don't know. [Pause] I guess they became blind just because the didn't need their sight. But I don't see how that could be passed on. (D 24, initial)

[The following are Stephanie's responses to her answers to the pretest question on the evolution of speed in a population of cheetahs.]

ST: I have a hard time forming opinions about this [question]. I really don't think we can form something just because we need it. (D 15, initial)

While the use/disuse and need explanations were offered by Stephanie, she clearly recognized that they were not plausible. Often students apply conceptions to explain natural phenomena that do not meet all the criteria of Posner et al. (1982) (Carey, 1985; Clough \& Driver, 1986; Gilbert, Watts, \& Osborne, 1982). It is important to consider that although Stephanie did not find the conceptions personally plausible, she understood them to be the scientific explanation for this phenomenon: "That's what they [scientists] say, but I just don't get it" [D 29]. She was experiencing learner dissatisfaction as she evaluated this conception, as Posner et al. (1982) describe.

By midyear, Stephanie's dissatisfaction with this conception grew and she had constructed a competing conception, mutation, as the origin of variation. At this point, although Stephanie was evaluating the competing conceptions, she had not chosen between the two.

\section{Midyear Framework.}

[The following are Stephanie's responses in an open-ended interview.]

R: So how do evolutionary changes happen then?

ST: It just seems that all the evolutionary changes take place because there was a need for it. But I just don't think we grow something for nothing. (D 186, midyear)

[The following are Stephanie's responses to the prediction interview in which she had to select the most probable mutation for a species of ice-age bear.]

ST: Well, mutations doesn't [sic] just happen because you want it to. It just sort of happens. . . . And so it, it's, if it's beneficial, it's gonna survive and help the species. If it's not, that one's going to die out real quick and not reproduce. (D 226, midyear)

By year end, Stephanie had completely rejected the use/disuse or need-based explanation for the production of variation in favor of mutation.

Year-End Framework.

[The following are Stephanie's responses to a card sort in which a population of rabbits changes from predominantly white in color to predominantly brown.] 
R: Okay, see if you can use any or all of these cards to explain an evolutionary event in a population of rabbits.

ST: Sure. Okay, I'd put all the white rabbits out first.

R: Okay.

ST: So they're all the same.

R: Okay.

ST: And the, ah, let's see. Then there is a mutation. . . And then so there are some brown rabbits produced. And, ah, the hawk comes-is that a hawk?

R: Yeah, a hawk or some predatory bird.

ST: Okay, and it starts eating the white rabbits. . . . So they start dying out and the brown ones start reproducing because they're not being seen and they're not getting eaten. And then pretty soon they're all brown because all the white ones died out and got replaced by brown rabbits.

R: Okay. . . . To hit a point home, you had the mutation happen before the hawk showed up.

ST: Yeah ...

$R$ : Would the mutation have happened without the hawk showing up, if the rabbits didn't need it?

ST: Yeah. (D 270-71, year-end)

[The following are Stephanie's responses to the prediction interview in which she had to select the most probable mutation for a species of ice age bear.]

R: Which one of them [mutations] is more likely to happen?

ST: I think all of them are equally likely to happen.

R: All of them? Why?

ST: Because it's a mutation. It's random! So, I mean, a mutation doesn't think about what it's going to do. . . . It just sort of happens. (D 269, year-end)

By the end of the study, Stephanie accepted and applied only one conception to explain this biological phenomenon based on the plausibility of the two competing conceptions. She underwent a process of wholesale change of a major organizing conception based on a rational assessment of the evidence. This pattern conforms to the description of conceptual change that would be expected with the application of Posner et al.'s (1982) normative model. However, it is important to consider that although comparison of the initial and year-end frameworks might make the change appear wholesale, it was actually a gradual process with holistic results.

\section{Incremental Change}

Often, the initial stages of the change of a single conception were characterized by the participant's use of a new term within a previously constructed explanation. Typically, the initial use was not accompanied by a full, scientific understanding, but instead an almost rote recall of an earlier use. This process was seen in Meredith's initial use of mutation in her explanation of the process of evolutionary change. At first she rejected mutations as a possible source of variation.

\section{Initial Framework.}

[The following are Meredith's responses to the pretest questions about the evolution of webbed feet in a population of ducks.] 
M: The trait of webbed feet in ducks, ah, I said, ah, they appear in ducks because they lived in water and needed to swim.

R: Why do you say that?

M: Well, ah, webbed feet allows, 1 mean, ah, better for better swimming. It was an evolved trait, wasn't it?

R: Uh-huh. [Yes]

M: And it's not a chance mutation, it was something that was necessary.

R: Okay, so how do things evolve?

M: Well, ah, it's mainly as far as when they need to, ah, adapt to certain conditions. (A 19, initial)

Soon after this comment, Meredith explained that she wasn't convinced of her knowledge of variation.

[The following are Meredith's responses to questions about the evolution of speed in a population of cheetahs.]

R: So, like this, try to think out loud. How do you think it [evolution of speed] would happen?

M: Ah, I don't know. I mean, this is that, obviously, I mean, it was necessary. . . . It needed to run faster, but I don't know how this happens. I mean. . . . That's kinda what you're asking, is how, what causes it and how it happens, and I don't know that.

R: Okay, you don't know.

M: I know it happens. I know it's one answer to something, but I don't know what it is. [Laughter] (A 24-25, initial)

Meredith first mentioned mutation after reading it on a pretest. At this point, it was clear that she did not understand what this term signified, but instead used it to fill a gap in her previous understanding of evolutionary change.

[The following are Meredith's responses to a pretest question about the evolution of webbed feet in a population of ducks.]

M: The population of ducks evolved webbed feet because [pause]. Okay, I didn't answer this question. I said the population of ducks evolved webbed feet because of a need to fit their environment. I mean, thus a mutation occurred.

R: So what is a mutation? How does it fit into all of this?

M: It's, it's the change that, ah, ah, an organism, or you can call it an organism, goes through to, ah, become more suited for the environment that they live in.

R: Ah, ah, how did, how did that happen? How do mutations happen?

M: Ah, I'm not too sure. (A 28, initial)

In later interviews, Meredith began to apply mutation in more of her explanations, gradually narrowing the scope of mutation's actions as she more closely defined the term. It was not until the midyear interview period that Meredith constructed a scientific conception of the process of mutation and its actions.

\section{Midyear Framework.}

[The following are Meredith's responses as she constructed a concept map.]

R: Ah, I want you to map how evolution works. What, ah, what concepts would you need to use? 
M: How it works? Is that what I'm trying to do?

R: Yeah, how the process works. . . . So, what concepts have you come up with so far?

M: Ah, evolution, mutation, species, and fittest. . . . Well, I'll say, ah, it's mutation . . . that produces a new characteristic. ... I want to say that, you know, there is a mutation that occurs . . . that produces a new characteristic and now it's got characteristics that allow species to be more able to be more fit for its environment, then that characteristic will be duplicated. ...

$R$ : Now, ah, a mutation, what does it do?

M: It, it's kind of a change in a characteristic of a species. . . I mean, but it's sometimes, the, I mean, the mutation might be for the worse. (A 221-223, midyear)

By year end, Meredith had rejected the need-based conception for the origin of variation in favor of its scientifically appropriate counterpart. However, her systematic usage of this conception came far after her initial, tentative, and uniformed proposal of this alternative. Such a gradual change in the meaning assigned to a term was also described by Fischer and Aufschnaiter (1993) in their study of the development of meaning making by students learning physics.

Related to Meredith's incremental conceptual change is the change experienced by Stephanie in her understanding of scope of evolutionary change. In this case, the student experienced incremental change in a conception, but without a change in the phrase she used to signify the conception.

\section{Initial Framework.}

[Written answer to the pretest question, "What is your personal opinion of the theory of evolution?"]

ST: I believe evolution is a possibility because of all of the evidence that supports the theory, such as Lucy and finding the ancestral bones. But I don't think, I don't completely believe that man crawled out of the sea a million years ago. [Soft laugh] Man may have evolved fully from Neanderthals, but not fish or one-celled organisms. I don't think just because I would decide to live in the ocean that my greatgrandchildren would have gills. That's pushing the evolution thing too far. (D 24-25)

This answer signifies Stephanie's (a) recognition of viable scientific evidence supporting evolution, (b) conception that a scientific description of evolution includes large-scale morphological changes dependent on a Lamarckian mechanism, and (c) personal conception that human evolution includes only subtle changes within hominids. Each one of these individual conceptions is important in describing Stephanie's initial conceptual framework; however, her conception of the plausible scope of evolutionary changes is an example of a major conception that underwent incremental changes over the scope of the study.

As demonstrated in her second concept map (Figure 1) and the preceding quote, Stephanie had two conceptions of evolutionary change. The one that she personally accepted was that evolution was a process of gradual, subtle changes that occurred within a kind of organism, "Man may have evolved fully from Neanderthals" (D 24-25). As Stephanie explained, "I could see how that could happen. Just because they're subtle changes. Just adaptation to your environment." (D 25)

In contrast to the conception she personally accepted, Stephanie understood that the scientific explanation for evolution involved a process of drastic changes that accounted for the original production of life ("development from one cell") and a subsequent series of large-scale 


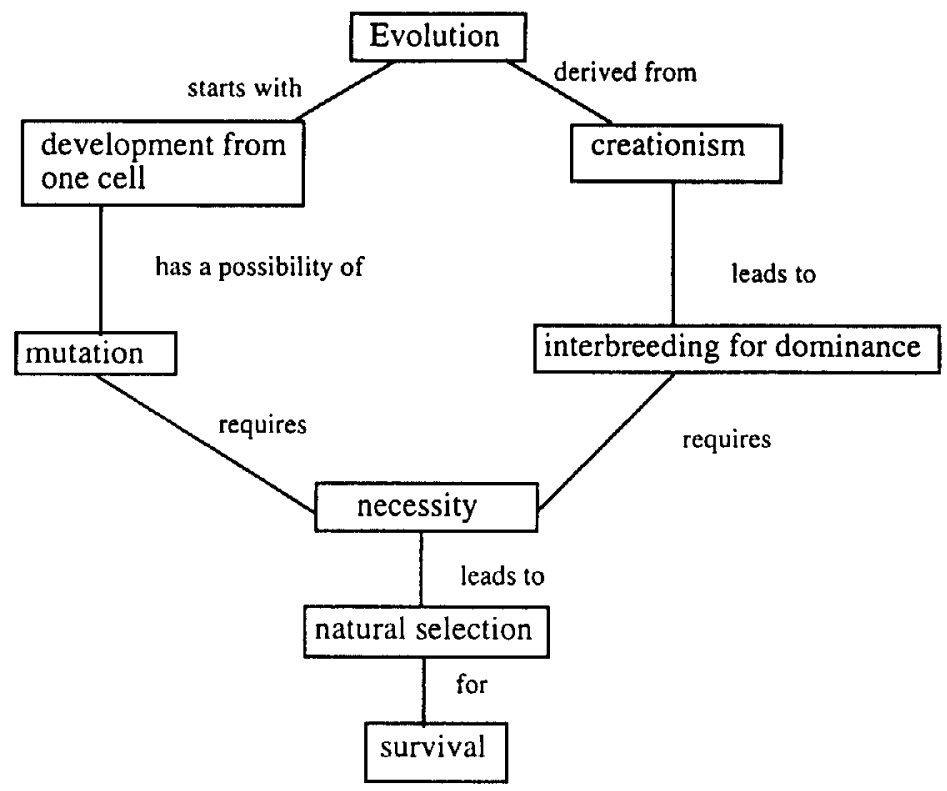

Figure 1. A representation of Stephanie's initial concept map drawn in response to the prompt, "Map your understanding of how evolution works."

morphological alterations which forced organisms to "totally change into other creatures." (D 94) Stephanie rejected this group of conceptions as being implausible:

ST: I think a species can evolve. . . Cheetahs, that's a species that just kind of grew, evolved into something better. But that whole thing about the amoebas [evolving into humans]. . . . I think that's really pushing the point. You know, when somebody says that. But you know they say it happened over millions of years. But even then, something had to just make something happen. If I didn't have it, I couldn't just grow into something myself. And I don't think the amoeba group could have evolved either. They don't, they don't have the traits to do that with. I don't see how it could happen. (D 28)

Stephanie had two systems of conceptions of the nature of evolutionary changes, the one that she accepted and personally applied, of "subtle changes" within a species, and the one that she understood science to hold but she personally rejected of large-scale changes between different groups of organisms.

\section{Midyear Framework.}

During the midyear period, Stephanie continued to explain that her personal understanding of evolution included acceptance of gradual, subtle changes within a group. This was more than just a rote answer as demonstrated by the graphics Stephanie selected in an interview about instances. When asked to pick the graphic which best represented her understanding of evolutionary change, Stephanie selected graphics that depicted subtle changes within similar organisms (Figure 2C and D in Appendix). However, at this point, what Stephanie understood to be a 
"subtle change" and "within a group" was undergoing revision. By the midyear period, Stephanie's personal understanding of evolution included changes that occur within a kind of organism (such as cheetahs) as well as accounting for changes between more different groups.

ST: I think maybe crocodiles came from dinosaurs and birds maybe came from dinosaurs. I mean, I can kinda see the connection there. But I can't see a connection between bacteria and an elephant. (D 182)

In an interview 2 weeks later, Stephanie began to incorporate this change in her formal description of evolutionary change:

ST: It [evolutionary change] could be drastic over time if you compare the changes between something over 10 million years ago and something today. That's a big, drastic change. . . . But over a couple of years, there's not drastic change. (D 223)

Year-end Framework.

The following written passage from Stephanie's posttest exam signifies her personal understanding of evolutionary change:

ST: I believe that evolution occurs in small beneficial doses to help a species survive, such as the DDT and the mosquitoes, but I am still not convinced that humans evolved from one-celled organisms that evolved out of the sea. I'm still a creationist, but I also believe that small changes that occur within a species through mutation helps that species to "evolve and survive." (Posttest 9)

This statement demonstrates that Stephanie personally understood evolution to include small, subtle changes within a species of organisms. Although her use of this formal statement remained constant throughout the scope of the study, the conception it represented underwent many changes. By year end, when Stephanie said "small changes," she meant that over a short period of time a species would undergo very subtle changes, but these changes may be accretionary over a long period of time ("It could be drastic over time"). Stephanie also used the phrase "within a species," but understood evolution to operate on a small scale within a species that could eventually lead to the production of very different groups. As described in the midyear framework, Stephanie understood her personal explanation for evolution to be congruent with the scientific conception of dinosaurs giving rise to birds, and the vertical changes within hominid lineages. Although her conceptions had gradually changed during the year of the study, the phrase she used to represent her meaning remained intact.

Two instances of incremental change documented in this study include Meredith's use of a term well before she understood its implication and Stephanie's reliance on a phrase that came to signify a very gradually changing conception. Meredith did not select the conception of mutation based on its plausibility. Instead, the new conception was immediately inserted into the prior existing explanation and only afterward did this new conception become more acceptable through subtle changes in meaning. Meredith's previous conception was undergoing a series of modifications to accommodate the new information she was learning. Stephanie continued to reject what she considered to be wide-scale evolutionary changes (such as amoebas to humans), but the scope of what she did accept as subtle evolutionary changes gradually increased. Such piecemeal and gradual conceptual change is similar to the pattern described by Nussbaum (1989, p. 538): 
[Conceptual change] forms a pattern in which the student maintains substantial elements of the old conception while gradually incorporating individual elements from the new ones.

Gradual conceptual change was also documented by Vosniadou (1991) in her study of conceptual development in astronomy, and Metz (1991) in her study of change in students' physics knowledge. Metz described both wholesale conceptual change and an incremental pattern. Within the incremental pattern, such as the differentiation of Dykstra, Boyle, and Monarch (1992), students' preexisting conceptions are transformed and serve as the basis for new conceptions. Documentation of subtle conceptual change of major paradigmatic conceptions calls into question the wholesale change described by Posner et al. (1982) as the sole pattern of conceptual change to be anticipated.

\section{Dual Constructions}

During two instances in the study, students failed to recognize their application of two logically incompatible conceptions. This was seen in Meredith's and Tyler's recognition of the random aspect of mutation, combined with their application of only beneficial mutations. In this interview excerpt, Tyler's acceptance of the random aspect of evolutionary change is stressed. [The following are Tyler's responses made during a word sort.]

T: Yeah, chance, because mutations are made by chance . . . in evolution. Ah, random, yeah, that describes evolution, because mutations are random things. I mean, you can't ask for them, they just happen (C 221, year end)

$\mathrm{R}$ : So you think that the majority of mutations that happen in a group are beneficial?

T: Ah, the majority yes, all no. (C 269, year end)

[The following are Tyler's responses to a card sort in which a population of rabbits changes from predominantly white in color to predominantly brown.]

T: So, all the white rabbits up here and no hawk. And something happens genetically.

R: Do you know the word for that?

T: Ah, like mutation...

R: Here's a question. You have something happening to make the first brown rabbit that's here. Ah, do you think that this happening has anything to do with the hawk?

T: Ah (long pause) no. (C 78, initial)

While in these interviews Tyler expressed one understanding of the nature of evolutionary changes, in the prediction interview involving mutations she applied a different conception. This conception linked need, environment, and mutation.

[The following are Tyler's responses to the prediction interview in which she had to select the most probable mutations for a species of ice-age bear.]

R: This is my ancestral mammal. It's kind of fat. It has kind of short hair and it makes a nest on the ground in sticks. That's how it nests. . . And then the ice age comes and it gets really cold.

T: Okay.

R: Something happens to produce new variation. Which one of these mutations would be more likely? This one gets long hair, this one [loses its hair], and this one learns to burrow in the ground. . . Which mutation do you think is most likely? Any of them?

T: Ah, most likely, let's see. Number two or three. 
R: Most likely, number two or three. Why did you say that?

T: Well, with that it's just natural. It's cold and now it's warm. It will change in order to take care of itself. (C 224-25, midyear)

Once the incompatibility of her conceptions was established, Tyler was questioned about this inconsistency.

[The following are Tyler's responses to the prediction interview in which she had to select the most probable mutations for a species of ice-age bear.]

R: We've looked at this [bear mutation graphic] before. This is the bear that had real short hair that nests on the ground. And then the ice age came and we were discussing the different mutations that were possible. And the answer that you had given then was that the long-hair mutation was possible.

T: Uh-huh. [Yes]

R: . . . You said the bear wouldn't mutate to the naked bear, because they'd freeze to death. So you still like that explanation pretty much?

T: Yeah.

R: Okay, and that same day you described mutations as, ah, random events. You know, mutations just happen. So you see any conflicts between mutations being random events and then your answer on that bear graphic?

T: I have no problem with that. (C 228-29, year end)

Inconsistent knowledge frameworks are well documented in science education literature (Carey, 1985; Clough \& Driver, 1986; Gilbert et al., 1982), and have been previously described for students' conceptions of evolution (Lawson \& Thompson, 1988). The notion of inconsistent knowledge frameworks contradicts past physics education research that describes conceptual change as a more consistent, linear process so that "conflicting conceptions cannot simultaneously be plausible to one person" (Hewson \& Thorley, 1989, p. 543). Tyler's case demonstrates that students often are not as logical or exclusive in their cognitive restructuring as researchers assume. The pattern of dual constructions suggests that learning of major paradigmatic conceptions occasionally does not entail the rebuilding of currently existing cognitive structures or the complete exchange of competing conceptions, but instead involves a process of accretion in which a second equivalent but competing conception is constructed and both are applied.

\section{Discussion}

How can we understand learning? If we view learning through a constructivist lens, we recognize the importance of active learners as they strive to reorganize what they know, to understand the world. The conceptual change model of Posner et al. (1982) is useful in that it highlights the importance of prior knowledge and the learner's efforts in understanding the process of how knowledge is restructured. However, originally the CCM was not considered to model all learning; instead, the intent was to model the wholesale change of major, paradigmatic conceptions. Subsequent applications have expanded the kinds of learning accounted for by the CCM, so that many consider even gradual changes within a conception to be explained by the CCM (Hewson \& Hewson, 1992).

Mayr (1982) explained that in the lifespan of a theory, after its initial acceptance, there follows a period of overextension in which the theory is stretched beyond its useful scope as it is applied to many phenomena. This process continues until enough disconfirming studies force the application of the theory back into more appropriate boundaries. Has the science education 
community found the CCM to be so useful that we have overapplied it to explain all forms of science learning? In this process, have we overlooked other forms of meaningful learning? It is time that we seriously review the CCM, its intended scope, and the implications it carries to model science learning.

The conceptual change theory of Posner et al. (1982) was designed to address only instances of accommodation for major, organizing conceptions. The holistic change they describe was supported in our study by the documentation of both cascade and wholesale patterns of conceptual change. However, the data from this study conflict with the relatively narrow description of change suggested by the normative work of Posner et al. Based on the additional patterns documented in this study, science educators should recognize that holistic conceptual change is not the only pattern to be expected in the learner's conceptual restructuring of major organizing conceptions. The patterns of conceptual change documented in this study that do not fit neatly within the CCM include incremental changes, as suggested by Nussbaum (1989) and Metz (1991), and dual constructions, in which competing conceptions are constructed and use of the prior conception is partially retained, as was suggested by Carey (1985) and Clough \& Driver (1986).

More important than the different patterns of conceptual change are the processes that lead to these pathways. The presence of incremental changes implies that the learner is subtly changing major conceptions for these conceptions to be useful. Thus, we do not see the comparison of competing conceptions, the abrupt cognitive dissonance, the overt choice between rival paradigms of thought that the CCM describes. Learning through incremental changes is a much more gradual, less dualist procedure. That is not to say that incremental changes are of less importance in shaping the learner's conceptual ecology and thus future learning events; instead, the shaping is often a far more gradual process than that allowed by the CCM.

The pattern of dual conceptions could be viewed in CCM terms as an aborted instance of conceptual change. However, such a categorization fails to reflect the learning that has occurred. Past research has documented many instances of inconsistent concepts in students' conceptual frameworks (Carey, 1985; Clough \& Driver, 1986; Gilbert et al., 1982). Such inconsistencies, although they contradict the logic implicit in the changes described by the CCM, are an integral part of the learning that occurs in our classrooms. While Tyler did not experience wholesale conceptual change, she was learning about evolution and her conceptual framework was being restructured, but she was far less logical in this restructuring than would be accepted by the CCM theorists. Lave's (1989) work in the situated nature of cognition in mathematics demonstrated that learners apply mathematic concepts in very different ways from academics; yet, these everyday practices represent the learner's attempts to make sense of practical situations. She used these differences to call into question the western definition of rationality implicit in current cognitive theories. This argument is supported by the work of Belenky, Clinchy, Goldberger, and Tarule (1986), who demonstrated that logical criteria for learning are used only by some categories of learners. Other learners are categorized by their tendencies to rely more heavily on intuition, instinct, and personal experience within specific contexts.

It is not our intent to suggest that particular students undergo cognitive restructuring in specific patterns. As seen in the case of Stephanie and Meredith, individual learners undergo cognitive restructuring that can follow a variety of patterns. Perhaps some students may be more prone to experience wholesale conceptual change because of their tendency to use logical criteria for evidence evaluation. This study did not investigate this contention. But as seen in Stephanie's case, the ability to experience wholesale conceptual change does not preclude learning through other patterns as well. Instead, we should recognize that there are a variety of pathways to learning a concept. 
The results of this study point out that the science education community needs to be far more deliberate in its descriptions of learning. Some pathways of learning of major organizing conceptions are understandable using the criteria outlined in the CCM. Other instances of learning major organizing conceptions, however, do not follow this description. Often learners are less logical, precise, and exclusive in their learning process than described by fundamentally rationally based cognitive theories. The CCM describes one kind of learning. Other important events of cognitive restructuring occur in our classrooms, and we need to begin to recognize and model these processes as well.

\section{Implications}

The focus of this study was to further clarify our understanding of conceptual change. We suggest that our understanding of cognitive restructuring requires modification. Just as the conceptual change theory (Posner et al., 1982) provides the theoretical foundation required to explain instances of wholesale conceptual change, further research and thought are needed to understand the wide range of learners in our classrooms, including those who are less logical but just as engaged in the learning process as those traditionally considered to undergo logically based wholesale conceptual change.

Further research is also needed to investigate the patterns of conceptual restructuring within other theoretical frameworks both in biology and other science disciplines. Possible questions include the following: Are the four patterns described in this research exhaustive of all conceptual restructuring of major, organizing conceptions? Are the patterns of change identical for both minor and major conceptions? In addition, much of the conceptual change documented in this study occurred during the course of a school year. A study which followed these participants for only a few days or weeks could easily have concluded that no conceptual change occurred. As suggested by Jimenéz (1992), studies designed to examine the process of conceptual restructuring should be mindful of the time frame of the research, to construct a more accurate picture of the learning process.

While we focused on the nature of conceptual change, ultimately the descriptions we generate should inform classroom practice. Future research should focus on the role of the conception of need as a phenomenological principle; instruction targeting this conception may prove to be a successful means of assuring conceptual change toward a scientific framework for evolution. In addition, future curricula should take into account the long time span required to construct a meaningful understanding of evolution. We suggest that not only should evolution be addressed early in the instructional sequence, this topic should be woven throughout biology instruction. Finally, instruction designed along the CCM may prove to be very fruitful in provoking conceptual change in a segment of our students (Bishop \& Anderson, 1990). However, this research demonstrates that not everyone restructures conceptions according to those guidelines, and alternate forms of instruction need to be integrated to reach the wide diversity of students in our classrooms.

\section{Appendix}

Materials and Samples of Interview Questions and Directions for Structured Interview.

\section{Concept Mapping.}

- Concept mapping (CM-1)-directions What I want you to do today, the big thing is, is to do a concept map for me. And I want you to do it on your understanding of evolution to this point. 
- Concept mapping (CM-2)-directions

I want you to draw a concept map about how evolution works.

- Concept mapping (CM-3)-directions

Using these five words, (evolution, mutation, change, population, natural selection),

I want you to draw a map explaining how evolution works. You can add any terms you need.

\section{Interview about Instances}

Adaptation, Taxonomy, Speciation, Species Concept, and Natural History.

In this set of interviews, students were shown drawings and photographs. The students were asked to discuss anything that occurred to them as they observed the graphics. Our use of the interviews about instances is substantially different from that of White and Gunstone (1992), who used the interviews to focus on examples and nonexamples of one concept. Our application was much broader, as we focused on the students' general knowledge of natural history. The graphics used for the first interviews about instances included:

1. A common egret fishing in white, choppy water.

2. A red octopus.

3. An elephant foraging from a tall tree in an otherwise empty field.

4. A litter of kittens, all of which are phenotypically different.

5. Three different bears: a grizzly, a brown bear, and a polar bear.

6. A purple wildflower.

7. A small, black sea turtle walking over white sand.

8. A fruit-eating bat feeding from a cactus.

9. A uniform population of cartoon rabbits.

10. Three different primates: a gorilla, a chimpanzee, and a human.

11. A phylogeny of humans including primates from gibbons to humans, entitled "A puzzling family tree."

12. A graphic depicting different species of Galapagos finches, their different bill structures, and food sources.

\section{Patterns of Evolutionary Change.}

In this set of interviews, students were shown a series of line drawings (Figure 2). The students were asked to select which of the four branches best depicted their ideas of evolutionary change. The students were also requested to explain their reasoning. Sample questions included:

1. Which tree best depicts evolutionary changes as you understand them?

2. Okay, so why did you pick that one?

3. So what was the deciding factor for you?

\section{Prediction Interviews.}

Three series of graphics were used in these structured interviews. The students were given the first graphic in the series, with an explanation of the situation. Then they were asked to make a prediction based on their observations. This prediction was written down as well as stated verbally. Afterward, the students were shown the second graphic in that series and were asked to make observations of the outcome of the situation. Finally, they were asked to explain any differences between their prediction and the outcome of the situation. 


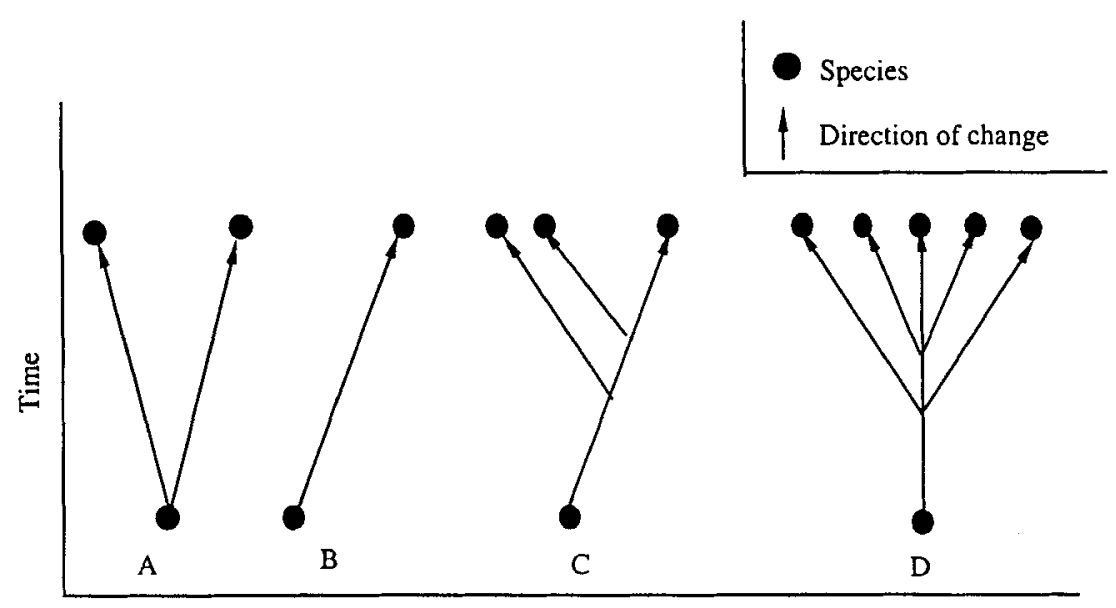

| Amount of phylogenetic change |

Figure 2. Line drawing of patterns of evolutionary change.

For the prediction interview involving knowledge of mutation (PI-2), a hand-drawn graphic was used to prompt participant responses. The graphic included a cartoon rendering of a bearlike mammal with a short, white pelage, standing next to a bed of vegetation. Three arrows led from this animal, with the words "ice age" superimposed. At the end of each arrow was another rendering of a bearlike animal. The first had a very long, thick pelage. The second had no hair, and the third looked identical to the first animal, but was standing next to a cave. As the participants looked over the graphics, they were asked the following questions:

The following is a prototypical species of bear. Notice he has short hair and is a ground dweller. The ice age comes to the place where this species lives. Of the three possible mutations seen here (becoming a cave dweller, gaining long hair, or losing all hair), which one or ones do you think are possible? Which one or ones are impossible? Why?

After the students made a prediction and explained their reasoning, they were asked the following questions:

All three mutations are possible. How does this coincide with your predictions?

\section{B-4: Sorting Task.}

For this interview, the students were randomly presented six graphics and were asked to use them to explain an evolutionary event of color change in a population of rabbits. The students were instructed that they could use any of the cards they wished, in any order, and that not all of the cards had to be used. As they were sorting, the students were reminded to think aloud and to voice as many of their thoughts as possible.

Six hand-drawn graphics were included in the series. The first included a population of white cartoon rabbits shown on a tan background. The second depicted a double helix with a broken segment. The third included a rabbit population on the same background, but this population included a majority of white individuals along with two brown members. The fourth graphic depicted this population with the addition of a predatory bird located in the periphery of 
the graphic. The fifth graphic included a rabbit population of the same size previously described, but with more tan individuals located on the tan background. In this graphic, the predator held a dead white rabbit. The final graphic included the predator and a rabbit population of the same size previously described, but with a majority of tan individuals.

\section{Word Sort.}

In this structured interview, the students were randomly presented a group of terms written on cards. They were instructed to select the terms which could be applied to evolutionary theory and those terms which could not. The students were reminded to talk as they sorted the terms, and were asked to explain their reasoning. The terms used include: design, drastic, success, need, random, chance, subtle, and order.

\section{References}

Belenky, M., Clinchy, B., Goldberger, N., \& Tarule, J. (1986). Women's ways of knowing: The development of self, voice, and mind. New York: Basic Books.

Bishop, B.A., \& Anderson, C.W. (1990). Student conceptions of natural selection and its role in evolution. Journal of Research in Science Teaching, 27, 415-427.

Bishop, B., \& Anderson, C.W. (1985). Evolution by natural selection: A teaching module (Occasional Paper No. 91). East Lansing, MI: Institute for Research on Teaching, Michigan State University.

Bogdan, R.C., \& Biklen, S.K. (1992). Qualitative research for education (2nd ed.). Boston: Allyn and Bacon.

Brown, D.E. (1995, April). Concrete focusing and re-focusing: A cross-domain perspective on conceptual change in mechanics and electricity. Paper presented at the annual meeting of the American Educational Research Association, San Francisco, CA.

Brumby, M.N. (1984). Misconceptions about the concept of natural selection by medical biology students. Science Education, 68, 493-503.

Carey, S. (1985). Conceptual change in childhood. Cambridge, MA: Bradford Books/MIT Press.

Chinn, C.A., \& Brewer, W.F. (1993). The role of anomalous data in knowledge acquisition: A theoretical framework and implications for science instruction. Review of Educational Research, 63, 1-49.

Clough, E.E., \& Driver, R. (1986). A study of consistency in the use of students' conceptual frameworks across different task contexts. Science Education, 70, 473-496.

Clough, E.E., \& Wood-Robinson, C. (1985). How secondary students interpret instances of biological adaptation. Journal of Biological Education, 19, 125-130.

Cummins, C.L., Demastes, S.S., \& Hafner, M.S. (Eds.). (1994). Special Issue: The teaching and learning of biological evolution. Journal of Research in Science Teaching, 31(5).

Cummins, C., Good, R., Demastes, S., \& Peebles, P. (in press). Reasoning using biological content: Relationships among evidence, theory, and interpretation. Journal of Research in Science Teaching.

Deadman, J.A., \& Kelly, P.J. (1978). What do secondary school boys understand about evolution and heredity before they are taught the topics? Journal of Biological Education, 12, $7-15$

Demastes, S. (1994). Factors influencing conceptual change in evolution: A longitudinal, multicase study. Unpublished doctoral dissertation, Louisiana State University, Baton Rouge, LA. 
Demastes, S.S., \& Good, R. (1993, April). A description of university students' conceptual change in evolution. Paper presented at the annual meeting of the National Association of Research in Science Teaching, Atlanta, GA.

Demastes, S.S., Trowbridge, J.E., \& Cummins, C.L. (1992). Information for science education literature on the teaching and learning of evolution. In R. Good, et al. (Eds.), Proceedings of the 1992 Evolution Education Research Conference (pp. 42-71). Baton Rouge, LA: Louisiana State University.

diSessa, A. (1993). Toward and epistemology of physics. Cognition and Instruction, 10, 105-225.

Driver, R., \& Easley, J. (1978). Pupils and paradigms: A review of literature related to concept development in adolescent students. Studies in Science Education, 5, 61-84.

Duit, R. (1991). Students conceptual frameworks: Consequences for learning science. In S. Glynn, R. Yeany, \& B. Britton (Eds.), The psychology of learning science (pp. 65-85). Hillsdale, NJ: Lawrence Erlbaum Associates.

Dykstra, D., Boyle, C., \& Monarch, I. (1992). Studying conceptual change in learning physics. Science Education, 76, 615-652.

Fischer, H.E., \& Aufschnaiter, S.V. (1993). Development of meaning during physics instruction: Case studies in view of the paradigm of constructivism. Science Education, 77, $153-168$.

Gilbert, J.K., Watts, D.M., \& Osborne, R.J. (1982). Students' conceptions of ideas in mechanics. Physics Education, 12, 62-66.

Glaser, B., \& Strauss, A. (1967). The discovery of grounded theory. New York: Adline.

Hewson, P.W. (1981). A conceptual change approach to learning science. European Journal of Science Education, 3, 383-396.

Hewson, P.W. (1982). A case study of conceptual change in special relativity: The influence of prior knowledge in learning. European Journal of Science Education, 4, 61-78.

Hewson, P.W., \& Hennessey, M.G. (1992). Making status explicit: A case study of conceptual change. In R. Duit, F. Goldberg, \& H. Niedderer (Eds.), Research in physics learning: Theoretical issues and empirical studies (pp. 176-187). Kiel, Germany: Institute for Science Education.

Hewson, P.W., \& Hewson, M.G. (1992). The status of students' conceptions. In R. Duit, F. Goldberg, \& H. Niedderer (Eds.), Research in physics learning: Theoretical issues and empirical studies (pp. 59-73). Kiel, Germany: Institute for Science Education.

Hewson, P.W., \& Thorley, N.R. (1989). The conditions of conceptual change in the classroom. International Journal of Science Education, 11, 541-553.

Jensen, M.S., \& Finley, F.N. (1994, March). Changes in students' understanding of evolution resulting from different curricular and instructional strategies. Paper presented at the annual meeting of the National Association for Research in Science Teaching, Anaheim, CA.

Jimenéz, A.M.P. (1992). Thinking about theories or thinking with theories? A classroom study with natural selection. International Journal of Science Education, 14, 15-21.

Kargbo, D.B., Hobbs, E.D., \& Erickson, G.L. (1980). Children's beliefs about inherited characteristics. Journal of Biological Education, 14, 137-146.

Lave, J. (1989). Cognition in practice. Cambridge: Cambridge University Press.

Lawson, A.E., \& Thompson, L.D. (1988). Formal reasoning ability and misconceptions concerning genetics and natural selection. Journal of Research in Science Teaching, 25, 733746.

Mayr, E. (1982). The growth of biological thought: Diversity, evolution, and inheritance. Cambridge, MA: Belknap Press of Harvard University Press. 
Metz, K.E. (1991). Development of explanation: Incremental and fundamental change in children's physics knowledge. Journal of Research in Science Teaching, 28, 785-797.

Millar, R. (1989). Constructive criticisms. International Journal of Science Education, I1, 587-596.

National Research Council. (1990). Fulfilling the promise: Biology education in the nation's schools. Washington, DC: National Academy Press.

Nussbaum, J. (1989). Classroom conceptual change: Philosophical perspectives. International Journal of Science Education, 11, 530-540.

Patton, M.Q. (1989). Qualitative evaluation methods. Beverly Hills, CA: Sage.

Pintrich, P.R., Marx, R.W., \& Boyle, R.A. (1993). Beyond cold conceptual change: The role of motivational beliefs and classroom contextual factors in the process of conceptual change. Review of Educational Research, 63, 167-199.

Posner, G.J., Strike, K.A., Hewson, P.W., \& Gertzog, W.A. (1982). Accommodation of a scientific conception: Toward a theory of conceptual change. Science Education, 66, 211-227.

Reiner, M. (1992). Patterns of thought on light, and underlying commitments. In R. Duit, F. Goldberg, \& H. Niedderer (Eds.), Research in physics learning: Theoretical issues and empirical studies (pp. 99-109). Kiel, Germany: Institute for Science Education.

Rutherford, F.J., \& Ahlgren, A. (1990). Science for all Americans. New York: Oxford University Press.

Schwedes, H., \& Schmidt, D. (1992). Conceptual change: A case study and theoretical comments. In R. Duit, F. Goldberg, \& H. Niedderer (Eds.), Research in physics learning: Theoretical issues and empirical studies (pp. 188-202). Kiel, Germany: Institute for Science Education.

Settlage, J. (1992). Organizing science teaching around instructional conversations. Unpublished manuscript.

Smith, E. (1991). A conceptual change model of learning science. In S. Glynn, R. Yeany, \& B. Britton (Eds.), The psychology of learning science (pp. 43-63). Hillsdale, NJ: Erlbaum.

Smith, E.L., Blakeslee, T.D., \& Anderson, C.W. (1993). Teaching strategies associated with conceptual change learning in science. Journal of Research in Science Teaching, 30, $111-$ 126.

Strike, K.A., \& Posner, G.J. (1985). A conceptual change view of learning and understanding. In L.H. West and A.L. Pines (Eds.), Cognitive structure and conceptual change (pp. 211232). London: Academic Press.

Strike, K.A., \& Posner, G.J. (1992). A revisionist theory of conceptual change. In R.A. Duschl and R.J. Hamilton (Eds.), Philosophy of science, cognitive psychology, and educational theory and practice (pp. 147-176). New York: State University of New York Press.

Vosniadou, S. (1991). Conceptual development in astronomy. In S. Glynn, R. Yeany, \&

B. Britton (Eds.), The psychology of learning science (pp. 149-177). Hillsdale, NJ: Erlbaum.

Wandersee, J.H., Mintzes, J.J., \& Novak, J.D. (1994). Research on alternative conceptions in science. In D. Gabel (Ed.), NSTA handbook of research on science teaching (pp. 177-210). New York: Macmillan.

White, R., \& Gunstone, R. (1992). Probing understanding. New York: Falmer Press.

Received October 7, 1994

Revised July 26, 1995

Accepted August 22, 1995 